\title{
Exploring functional fungi on organic matter decomposition of oil palm empty bunches as bio-resource in land remediation
}

\author{
BURHANUDDIN RASYID ${ }^{1, \boldsymbol{\nu}}$, AMBO ALA ${ }^{2}$, TUTIK KUSWINANTI ${ }^{3}$, SUKRIMING SAPARENG ${ }^{4}$ \\ ${ }^{1}$ Department of Soil Science, Faculty of Agriculture, UniversitasHasanuddin. Jl. Perintis Kemerdekaan Km. 10, Tamalanrea, Makassar 90245, South \\ Sulawesi, Indonesia. Tel./fax.: +62-411-586014, `email: burrasyid@unhas.ac.id \\ ${ }^{2}$ Department of Agronomy, Faculty of Agriculture, Universitas Hasanuddin. Jl. Perintis Kemerdekaan Km. 10, Tamalanrea, Makassar 90245, South \\ Sulawesi, Indonesia \\ ${ }^{3}$ Department of Plant Protection, Faculty of Agriculture, Universitas Hasanuddin. Jl. Perintis Kemerdekaan Km. 10, Tamalanrea, Makassar 90245, South \\ Sulawesi, Indonesia \\ ${ }^{4}$ Department of Agrotechnology, Faculty of Agriculture, Universitas Andi Jemma. J1. Sultan Hasanuddin No. 13, Palopo 91911, South Sulawesi, \\ Indonesia
}

Manuscript received: 24 March 2020. Revision accepted: 24 August 2020.

\begin{abstract}
Rasyid B, Ala A, Kuswinanti T, Sapareng S. 2020. Exploring functional fungi on organic matter decomposition of oil palm empty bunches as bio-resource in land remediation. Biodiversitas 21: 4247-4252. Organic matter of oil palm by-product has the potential to be applied for land remediation. The objective of this experiment was to explore functional fungi on the decomposition effectivity of oil palm empty bunches. Samples were collected from oil palm plantation fields and oil palm factory. Isolated fungi from decomposed material (trunks and rod) were Penicillium sp., Pleurotus sp., Fusarium sp., Chrysosporium sp., and Aspergillus sp. Fungi in the empty fruit branches were identified as Absidia sp., Tremella sp., and Trichoderma sp., Phytophthora sp., Ulocladium sp., and Chaetomium sp. Within all collected fungal isolates, Pleurotus sp., Trichoderma sp., and Tremella sp. were selected as functional fungi based on the results of the highest lignocellulolytic ability (50-75\%). The degradation rate of organic matter of each functional fungi was observed as Trichoderma sp. (24.0\%), Tremella sp. (20.0\%), and Pleurotus sp. (16.0\%). Change of C/N ratio as a result of decomposition showed significant difference compared to control with 22.09 by Trichoderma sp., 24.26 by Pleurotus sp., 26.68 by Tremella sp. and 36.58 in control. This study could be concluded that exploring functional fungi can potentially be applied in the decomposition of oil palm by-product effectively.
\end{abstract}

Keywords: Bio-resource, decomposition, functional fungi, land remediation

\section{INTRODUCTION}

Oil palm plantation in Indonesia is one of the largest agriculture by-product producers. Oil palm empty bunches and mill effluent are two kinds of waste materials related to oil palm growth and oil production process. As an example, in the processing of 1 ton of fresh bunches had to leave around $23 \%$ of oil palm empty bunches (Udoetok 2012; Ishani and Benjamin 2014; Solikhin, et al. 2016). This material could be brought an environmental problem but also usefulness when well managed. It had relatively big size, high lignocellulolytic content, high $\mathrm{C} / \mathrm{N}$ ratio, and difficult to decompose, but it also built up with macro and micronutrient (Kurnin et al. 2016; Madusari et al. 2018). This organic matter has the potential to be used in improving soil quality and productivity.

The utilization of oil palm by-product, in general, is direct application as mulch, burning in the waste incinerator, or open dumping. These waste management models have been shown failure because it has an advantage in bio-physicochemical properties. The advanced management method could be improved in biophysical process. Involving biological processes in utilization oil palm empty bunches is a new important approach (Amira et al. 2013). An understanding of the role of the microorganism in decomposing organic matter is applied in processing oil palm empty bunches to become more valuable products. Introducing functional fungi in the degradation process of organic material has been well studied but very little information is available regarding degradation of oil palm empty bunches. Activation of microbes as bio-degradable agents to conduct degradation or transformation of organic matter is dependent on the structure and chemical composition (Bala et al. 2014). Cellulose, hemicelluloses, and lignin are the main components of the fiber of oil palm empty bunches. Among these chemical components, cellulose is easier to degrade. Lignin is the strongest more complex compound with a functional group such as hydroxyl, carbonyl, methoxy, and low dissolves in water (Huang et al. 2013; Janusz et al.2013; Cragg et al. 2015). In the degradation process, cellulose is strongly binding by lignin so it needs to be separate to produce nutrient-rich material.

White-rot fungus has been shown well capability in the degradation of main polymers such as cellulose and hemicelluloses in organic materials. The ability of these fungi to degrade lignin compound arise from enzymatic production such as lactase, lignin peroxidase, and Mnperoxidase (Sigoillot, et al. 2012; Amira et al. 2013; Asrul, et. al. 2018). In many issues on the utilization of microbes to decompose organic matter is still limited to find 
functional isolate or fungi with high degradable rate. The decomposition of oil palm empty bunches is still challenged to find more specific fungi. Exploring isolate is an important process to collect isolate or species related to it. This is an interactive process between decomposition organic matter and soil microbe which affected by rhizosphere conditions (Fontaine et al. 2014). This experiment was conducted to collect and find effective isolate to be used as functional fungi in degradation oil palm empty bunches. The results of this experiment will be applied in decomposition oil palm empty bunches for organic material or bio-resources in land reclamation.

\section{MATERIALS AND METHODS}

\section{Materials}

Oil palm empty bunches were collected from the oil palm factory and plantation area in Sub-districts of Burau and Malangke, North Luwu District, South Sulawesi, Indonesia. Laboratory study was conducted at Faculty of Agriculture, Hasanuddin University, Makassar, Indonesia. Sample preparation, isolation, and analysis of functional fungi were done in the Laboratory of Agricultural Biotechnology Research and Development Center, and organic matter analysis in the Laboratory of Soil Chemistry and Fertility.

Sampling material was taken from decomposing oil palm empty bunches directly from the field and then cleaned by using alcohol $(70 \%)$. Potato dextrose agar (PDA) medium was used for starting culture. Malt extract agar (MEA), and Malt peptone agar (MPA) media were applied for purification culture. Functional characterization was carried out by using some materials as: Pikovskaya medium, titrosol, ammonium molybdate, and calcium antimol tartrate. The CDA medium, Remazol brilliant blue, and other chemical materials were also used in this experiment to complete all subject analysis in selected fungi.

\section{Methods}

Collection and characterization sample

All the fungal samples collected from the field were cultured on PDA medium to initiate their growth from source material. All type of fungal growth on PDA medium was removed to be selected as functional fungi. Three kinds of medium (PDA, MEA, and MPA) were used to recultured fungi from a general medium. Samples on this medium were incubated for 7 (seven) days. In order to test the specific function of selected fungi, these were characterized morphologically based on macroscopic and microscopic observations. The growth rate, colony color, elevation and shape of the colony's edge was the component on macroscopic observations. The shape of spore and conidiophores was observed as microscopic characteristics under a light microscope.

\section{Decomposition capacity of selected fungi}

The advanced analysis was done to measure the decomposition capacity of selected fungi. Enzymatic and organic material measurements include estimation of lignocellulolytic enzyme, fiber content, organic carbon, and nitrogen content. Qualitative analysis of the lignocellulolytic enzyme was performed in CDA medium with remazol blue. This medium was prepared in 5 (five) parts which were each part added with $0.1 \%$ lignocellulose substrate as cellulose, lignin, pectin, amylose, and chitin. Measurement of enzyme activities using the scoring method based on the ratio of the diameter of the change zone in medium to the total diameter of the medium. Score scale was arranged from $1(+)(\leq 25 \%), 2(++)(25-50 \%), 3$ $(+++)(50-75 \%), 4(++++)(\geq 75 \%)$. Three species were selected based on the best performance of the experiment. Selected fungi were inoculated to oil palm empty bunches, and it composted for three months. Measurement of some parameters as decreasing of lignin, nutrient content, and $\mathrm{C} / \mathrm{N}$ ratio was done during the composting period.

\section{Data analysis}

Statistical data analysis was performed using SPSS ver. 22 computer package. Post hoc comparisons of means using DMRT test was done when a significant difference was found in the calculated parameter.

\section{RESULTS AND DISCUSSION}

\section{Collection and selection isolate}

Total of 32 rot fungus isolates was isolated from two group source: 15 isolates from decomposed oil palm, rod, and 17 isolates from empty bunches. All isolates were characterized to species level. Species of Trichoderma, Aspergillus, and Pleurotus were identified as dominant fungi from the site of collected sample (Table 1). Among 32 collection isolates analyzed to test enzymatic characteristics in decomposing organic matter, 15 isolates were selected which had derived from 7 isolates of decomposed material and 8 isolates of empty bunches. The selected isolates were also confirmed that two stages test have been shown different kinds of active fungus derived from the organic matter source. Yeoh et al. (2012) had been explained the differences in their access form of carbohydrate and product of enzyme activity which are also dependent on chemical constituents of the resource.

Table 1. Species and amount of isolates collection from two field sources

\begin{tabular}{llc}
\hline Source & Species & $\begin{array}{c}\text { Amount of } \\
\text { isolate }\end{array}$ \\
\hline Decomposed material & Penicillium $\mathrm{sp}$. & 3 \\
(trunks and rod) & Pleurotus $\mathrm{sp}$. & 4 \\
& Fusarium $\mathrm{sp}$. & 2 \\
& Chrysosporium $\mathrm{sp}$. & 2 \\
& Aspergillus $\mathrm{sp}$. & 4 \\
Empty bunches & Tremella sp. & 3 \\
& Trichoderma $\mathrm{sp}$. & 6 \\
& Phytophthora $\mathrm{sp}$. & 2 \\
& Ulocladium $\mathrm{sp}$. & 2 \\
& Chaetomium $\mathrm{sp}$. & 2 \\
& Absida $\mathrm{sp}$. & 2 \\
\hline
\end{tabular}



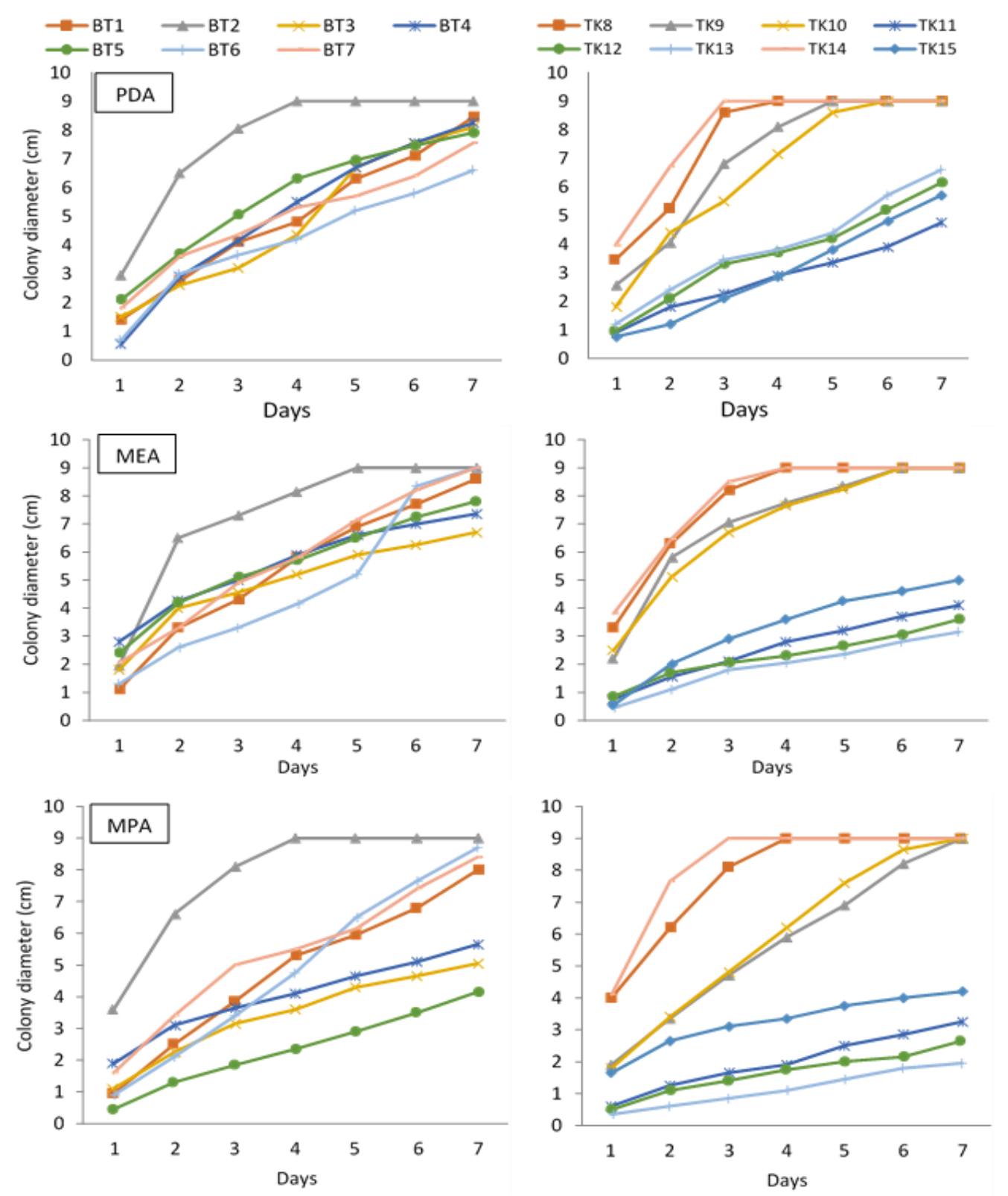

Figure 1. Growrh rate of selected isolate in three culture medium (PDA, MEA and MPA) during 7 days incubation. (BT: Decomposed material, TK: Empty bunches)

Baon et al. (2012) indicated that effect of the environmental conditions could be another possible factor to make the different kind decomposers in process of transformation of organic matter. Depending on two distinct sources of organic matter, the growth rate of decomposer was observed (Figure 1). Cultured selected isolates in three types of medium were shown a growth rate in decomposed material faster than empty bunches. The effectiveness of biodegradation of lignocellulolytic microbes in different media has been reported in some research such as the activity of cellulase in liquid medium using wheat bran as carbon source (Sorgatto et al. 2012), lignocellulolytic activity in solid-state fermentation
(Choudhary et al. 2016). In the case of oil palm empty fruit bunch decomposition, Shahriarinour et al. (2011) reported the effect of different fermentation substrates in the activity of Aspergillus terreus. The rate of colony formation in decomposed material tends in the same pattern as compare to empty bunches. There are prominent species $(\mathrm{BT} 2=$ Pleurotus sp.) in decomposed source while another species was spread in a group with no much different tendency. Two groups of active microbes were observed in case of fungal growth in empty bunches. The first group was dominated by Trichoderma sp. (TK 9, TK 10, and TK 14) and Tremella sp. (TK 8) has higher colony formation, and the second group has a lower colony formation. 


\section{Enzymatic decomposition characteristics}

The performance of three isolates in the previous test was used as the basis for selecting it as functional fungi. Determining functional fungi was decided through an enzymatic test. A lignocellulolytic enzyme is one of the secondary metabolites produced by decomposer fungi (Castro and Mario 2012). The existence of this enzyme is characterized by the presence of clear zones formed around the growth of the isolates on the CDA medium. The response of 15 selected isolates to the produce of the lignocellulolytic enzyme was shown in Table 2 .

Isolate producing high enzyme (clear zone more than $75 \%$ ) was shown by isolate BT2 (Pleurotus sp.) and isolate TK14 (Trichoderma sp.). In the medium category by forming between $50-75 \%$ was shown by BT6, BT7 (Aspergillus sp.), TK8 (Tremella sp.), and TK9, TK10 (Trichoderma sp.). Overall isolates produce variations in lignocellulolytic enzyme with decomposed material source had high variation in enzyme production in comparison to empty bunches. Within this variation, some species like Pleurotus sp., Trichoderma sp., Tremella sp., and Aspergillus sp. have enzyme composition high activity. However, to determine functional isolates, the results of previous tests were still used as evaluation of materials. Despite, Aspergillus sp., had complete and high lignocellulolytic enzyme, activity; historically it has slow and small growth response in a previous test. Shahbaz et al. (2017) explained that the increase of enzyme activities has a correlation with residue-metabolizing soil microorganisms and it could be indicated as soil organic matter cometabolism.

\section{Lignocellulolytic decomposition effectivity}

Decomposition value of incorporated oil palm empty bunches using these fungi shown specific descriptions on fungi effectivity. This decomposer community's effectivity has linked to the organism's physiology which has a correlation to the organic matter properties (Leifeld and von Lützow 2014). Based on the composition of lignocellulolytic content and decreasing in weight after 8 weeks of incubation, both organic matter sources have a different response to the kind of incubated fungi (Table 3). The lignocellulolytic composition of decomposed material had range value of hemicelluloses (4.69-7.15\%), cellulose (15.87-21.14\%), lignin (28.41-33.05\%), and decreasing weight $(2.0-16 \%)$. In case of empty bunches, the range value was $3.76-7.10 \%$ of hemicellulose, $16.75-22.31 \%$ of cellulose, $27.08-33.12 \%$ of lignin, $1.6-24.0 \%$ of decreasing weight. The value informed differentiation of microbe activity during the decomposition process. It could be related to the composition of the acting-enzymatic system which consisted of each fungi species. The enzymatic system in fungi composed of ligninolytic enzymes, hydrolytic enzymes, and nonenzymatic oxidative systems which responsible in degradation process of lignocellulose (Andlar et al. 2018). In general range value, not much different result was found in all evaluated parameters, except in decreasing the weight of TK 14 sample (Trichoderma sp.). It was presented the highest activity as the lowest content of lignin (27.08\%) and reduced weight to $24 \%$. The effects of lignin on residue decomposition have been explained by Stewart et al. (2015).

This value clarified how the decomposition process occurred as an interrelated factor between organisms, the quality of organic material, and the environment (Kaffenberger and Schilling 2015; Krishna and Mohan 2017). Therefore, rate of decomposition could be quickly or slowly depending on the ready accessibility of the organism, and the availability of energy and carbon for biosynthesis (Zibilske and Bradford 2007; Dutta and Dutta 2016). Change of all properties measured in decomposed material after 8 weeks incubation for fungi with the highest result was decided as functional fungi, i.e.: Pleurotus sp., Tremella sp., and Trichoderma sp.

Table 2. Lignocellulolytic enzyme production (\%) in decomposer fungus isolates based on the clear zone formed in CDA culture medium

\begin{tabular}{|c|c|c|c|c|c|}
\hline Isolate & Lygnase & Chitinase & Pectinase & Cellulose & Amylase \\
\hline BT1 & ++ & + & + & ++ & ++ \\
\hline BT2 & ++++ & +++ & +++ & ++++ & ++++ \\
\hline BT3 & ++ & +++ & ++ & + & ++ \\
\hline BT4 & + & + & ++ & + & ++ \\
\hline BT5 & ++ & + & ++ & ++ & ++ \\
\hline BT6 & +++ & +++ & +++ & ++++ & ++++ \\
\hline BT7 & ++++ & ++ & +++ & +++ & ++++ \\
\hline TK8 & ++++ & ++++ & +++ & +++ & +++ \\
\hline TK9 & ++++ & +++ & +++ & ++++ & +++ \\
\hline TK10 & ++++ & +++ & +++ & +++ & +++ \\
\hline TK11 & + & ++ & ++ & + & +++ \\
\hline TK12 & + & ++ & + & +++ & +++ \\
\hline TK13 & ++ & + & + & ++ & ++ \\
\hline TK14 & ++++ & ++++ & +++ & ++++ & ++++ \\
\hline TK15 & + & + & + & + & ++ \\
\hline
\end{tabular}

Note: + : $<25 \%$; ++: $25-50 \%$; +++: $>50-75 \%$; ++++: $>75 \%$, based on the area of the clear zone formed in CDA culture medium, BT: Decomposed material, TK: Empty bunches 


\section{Functional fungi capacity}

Incubation of empty bunches was carried out using selected fungi for 8 weeks to measure decomposer capacity properties. Duncan's test results showed that the highest content of C-organic, N-total, $\mathrm{P}_{2} \mathrm{O}_{5}$, and $\mathrm{K}_{2} \mathrm{O}$ was obtained in Trichoderma sp., and it is significantly different from other treatments of inoculated fungi (Table 4). Besides, the analysis of this parameter was also indicated decreasing in $\mathrm{C} / \mathrm{N}$ ratio and increasing of $\mathrm{C}$ and $\mathrm{N}$ content compared to the control without fungi application. Furthermore, Trichoderma sp. was strongly affected by a change of decomposition properties with the lowest $\mathrm{C} / \mathrm{N}$ ratio (27.38), followed by Pleurotus sp., (32,81), and Tremella sp. (34.33) compared to the control (39.23). In conversely, it showed differences in $\mathrm{C}$-organic with the highest content by Tremella sp. (21.63\%) and N-total content by Trichoderma sp. $(0.65 \%)$. Remarkably, the $\mathrm{C} / \mathrm{N}$ ratio of decomposed material was depending on the composition of $\mathrm{C}$ and $\mathrm{N}$ content as it found in control which was lower in both content but it highest in $\mathrm{C} / \mathrm{N}$ ratio. This ratio describes the portion of $\mathrm{C}$ per unit $\mathrm{N}$ needed by microorganisms in decomposition activity. Ishak et al. (2014) explained that this process reduced the $\mathrm{C} / \mathrm{N}$ ratio by converting organic $\mathrm{C}$ to $\mathrm{CO} 2$, and loss of nitrogen in the form of $\mathrm{NH}_{3}$. In addition, Young et al. (2005) found that high nitrogen content is determined by the initial nitrogen content of raw materials. Increasing the concentration of nitrate-nitrogen (NO3-N) at the end of the composting process increases the total nitrogen content. However, ammonium nitrate (NH4$\mathrm{N}$ ) which is high in the early stages of composting gradually decreases until the compost is produced. Regarding the effect of a combination of fungi, Pan et al. (2012) was found that nitrogen content increased significantly compared to a single inoculation.

The $\mathrm{C} / \mathrm{N}$ ratio was used to indicating mineralization and immobilization of nitrogen during the decomposition process $(\mathrm{Li}$ and $\mathrm{Li} 2015)$. The $\mathrm{C} / \mathrm{N}$ ratio less than 20 indicates $\mathrm{N}$ mineralization, and if more than 30 indicate $\mathrm{N}$ immobilization occurs. For compost production, the $\mathrm{C} / \mathrm{N}$ ratio value less than or equal 25 indicated the stable or mature condition (Shilev et al. 2007). The $\mathrm{C} / \mathrm{N}$ ratio in this experiment was found 36.58; 24.38; 26.68 and 22.09 for control treatment, and inoculated treatment by Pleurotus sp., Tremella sp., and Trichoderma sp. The result showed that all treatments except K0 (without fungi inoculation) the $\mathrm{C} / \mathrm{N}$ ratio value was in the optimum range $(\leq 25)$.
The decomposition of oil palm empty bunches could be done effectively using functional fungi as their characters with strong capacity in transforming organic material (Mohammad et al. 2012). There were thirty-two fungus isolates collected as resources in the selection of functional fungi. Pleurotus sp. (collected from decomposed oil palm rod), Tremella sp., and Trichoderma sp. (collected from empty bunches) were selected as functional fungi. Many factors affect the ability of decomposer fungi to degrade lignocellulolytic components (Manavalan, et al. 2015). These factors include differences in fungal strains and degraded substrates. In this study, the hemicellulose component had the lowest level compared to lignin and cellulose. All selected isolates have high performance in enzymatic decomposition properties and lignocellulolytic decomposition effectivity. In addition, these isolates also showed significant differences in chemical and organic matter composition properties of decomposition product and nutrient mineralization. The differences and increasing of nutrient mineralization occurs in the order of Trichoderma sp. (TK14) > Tremella sp. (TK8) > Pleurotus sp. (BT2) > Control (K0).

Table 3. Composition of lignocellulolytic content and decreasing weight after 8 weeks incubation

\begin{tabular}{|c|c|c|c|c|}
\hline \multirow{2}{*}{ Treatment } & \multicolumn{3}{|c|}{ Lignocellulolytic composition (\%) } & \multirow{2}{*}{$\begin{array}{c}\text { Decreasing } \\
\text { weight } \\
(\%)\end{array}$} \\
\hline & Hemicellulose & Cellulose & Lignin & \\
\hline Control & 10.20 & 24.02 & 38.25 & 0.0 \\
\hline BT1 & 7.15 & 21.14 & 32.30 & 2.4 \\
\hline BT2 & 4.69 & 15.87 & 28.41 & 16.0 \\
\hline BT3 & 6.21 & 22.43 & 31.06 & 2.0 \\
\hline BT4 & 6.30 & 19.87 & 30.32 & 3.2 \\
\hline BT5 & 5.27 & 20.54 & 33.05 & 4.0 \\
\hline BT6 & 5.05 & 18.16 & 29.15 & 4.0 \\
\hline BT7 & 4.98 & 18.97 & 30.45 & 6.0 \\
\hline TK8 & 4.01 & 16.75 & 27.60 & 20.0 \\
\hline TK9 & 4.76 & 17.98 & 27.15 & 12.8 \\
\hline TK10 & 3.97 & 18.93 & 27.85 & 10.0 \\
\hline TK11 & 7.01 & 21.32 & 31.45 & 2.0 \\
\hline TK12 & 6.98 & 20.65 & 32.76 & 1.6 \\
\hline TK13 & 7.10 & 22.31 & 33.12 & 2.0 \\
\hline TK14 & 3.76 & 17.65 & 27.08 & 24.0 \\
\hline TK15 & 6.80 & 22.05 & 31.24 & 2.0 \\
\hline
\end{tabular}

Table 4. Compost chemical properties of oil palm empty bunches inoculated with functional fungi

\begin{tabular}{|c|c|c|c|c|c|c|}
\hline \multirow{2}{*}{ Treatments } & C-organic & $\mathbf{N}$ total & $\mathbf{P}_{2} \mathbf{O}_{5}$ & $\mathbf{K}_{2} \mathbf{O}$ & \multirow{2}{*}{ Ratio C/N } & \multirow{2}{*}{ pH } \\
\hline & \multicolumn{4}{|c|}{$\%$} & & \\
\hline Control (K0) & $13.17^{\mathrm{c}}$ & $0.36^{\mathrm{c}}$ & $0.83^{\mathrm{c}}$ & $4.12^{\mathrm{b}}$ & $36.58^{\mathrm{b}}$ & $7.84^{\mathrm{a}}$ \\
\hline Pleurotus sp. (BT2) & $18.68^{\mathrm{b}}$ & $0.77^{\mathrm{b}}$ & $2.32^{\mathrm{b}}$ & $6.32^{\mathrm{ab}}$ & $24.26^{\mathrm{a}}$ & $8.23^{\mathrm{a}}$ \\
\hline Tremella sp. (TK8) & $21.34^{\mathrm{b}}$ & $0.80^{\mathrm{b}}$ & $2.35^{\mathrm{b}}$ & $6.64^{\mathrm{ab}}$ & $26.68^{\mathrm{a}}$ & $8.14^{\mathrm{a}}$ \\
\hline Trichoderma sp. (TK14) & $26.95^{\mathrm{a}}$ & $1.22^{\mathrm{a}}$ & $2.61^{\mathrm{a}}$ & $8.12^{\mathrm{a}}$ & $22.09^{\mathrm{a}}$ & $8.20^{\mathrm{a}}$ \\
\hline
\end{tabular}

Note: * the numbers followed by the same letter in the same row are not significantly different $(\mathrm{DMRT}$ test, $\mathrm{P}=0.05)$ 
The result was shown in line with lignocellulolytic enzyme production where Trichoderma sp. (TK14) produced the highest of this enzyme. The presence of this functional fungus as an active microbial community provides the important role of fungi in the mineralization of organic matter (Sandra et al. 2011). Decreasing of $\mathrm{C} / \mathrm{N}$ ratio in all fungal treatments accompanied by the formation of nutrients showed the value of decomposer functional fungi to be applied in the decomposition of organic matter, especially for oil palm empty bunches. Based on these results, it could be concluded that functional fungi have a high capacity to be utilized as bio-resource to produce decompose material for land reclamation.

\section{REFERENCES}

Amira RD, Roshanida AR, Mohd-Setapar SH, Rosli MI. 2013. Biodegradation oil palm residues into compost using filamentous fungi. Adv Sci Let 12 (5): 3529-2533.

Andlar M, Rezić T, Marđetko N, Kracher D, Šantek B. 2018. Lignocellulose degradation: An overview of fungi and fungal enzymes involved in lignocellulose degradation. Eng Life Sci 2018: 1-11. DOI: 10.1002/elsc.201800039.

Asrul L, Rahim I, Kuswinanti T, Rasyid B, Nasruddin A. 2018. Effect of cocoa pod husk compost produced using rot fungi on the growth of cocoa seedlings. OnLine J Biol Sci 18 (1): 69-73. DOI: 10.3844/ojbsci.2018.69.73.

Bala JD, Lalung J, Ismail N. 2014. Palm oil mill effluent (POME) treatment "Microbial communities in an anaerobic digester": A Review. Intl J Sci Res Publ 4 (6): 1-24.

Baon JB, Wedhastri S, Kurniawan A. 2012. The ability of phosphate solubilizing bacteria isolated from coffee plant rhizosphere and their effects on robusta coffee seedlings. J Agri Sci Tech 2: 1064-1070.

Casrtro YP, Mario VL. 2014. Biodegradation kinetics of oil palm empty fruit bunches by white-rot fungi. Intl Biodeter Biodegrad 91: 24-28

Choudhary M, Sharma PC, Jat HS, Nehra V, McDonald AJ, Garg N. 2016. Crop residue degradation by fungi isolated from conservation agriculture fields under rice-wheat system of North-West India. Intl J Recycl Org Waste Agricult 5: 349-360. DOI: 10.1007/s40093-0160145-3

Cragg SM, Beckham GT, Bruce NC. 2015. Lignocellulose degradation mechanisms across the tree of life. Curr Opin Chem Biol 29: 108-19.

Dutta H, Dutta A. 2016. The microbial aspect of climate change. Energ Ecol Environ 1: 209-232. DOI: 0.1007/s40974-016-0034-7

Fontaine S, Henault C, Aamor A, Bdioui N, Bloor JMG, Maire V, Mary B, Revaillot S, Maron PA. 2011. Fungi mediate long term sequestration of carbon and nitrogen in soil through their priming effect. Soil Biol Biochem 43: 86-96.

Huang XF, Santhanam N, Badri DV, Hunter WJ, Manter, DK, Decker SR, Vivanco JM, Reardon KF. 2013. Isolation and characterization of lignin-degrading bacteria from rainforest soils. Biotechnol Bioeng 110: $1616-26$

Ishak NF, Ahmad AL, Ismail S. 2014. Feasibility of anaerobic cocomposting empty fruit bunch with activated sludge from palm oil mill wastes for soil conditioner. Phys Sci 25 (1): 77-92.

Ishani M, Benjamin KS. 2014. Palm oil-based biofuels and sustainability in Southeast Asia: A review of Indonesia, Malaysia, and Thailand. Renew Sustain Energ Rev 37: 1-12.

Janusz G, Kucharzyk KH, Pawlik A. Staszczak M, Paszczynski AJ. 2013. Fungal laccase, manganese peroxidase and lignin peroxidase: gene expression and regulation. Enzyme Microb Technol 52: 1-12.

Kaffenberger JT, Schilling JS. 2015. Comparing lignocellulose physiochemistry after decomposition by brown rot fungi with distinct evolutionary origins. Environ Microbiol 17: 4885-4897.
Krishna MP, Mohan, M. 2017. Litter decomposition in forest ecosystems: a review. Energ Ecol Environ 2: 236-249. DOI: 10.1007/s40974-0170064-9.

Kurnin N, Ismail MHS, Yoshida H, Izhar S. 2016. Recovery of palm oil and valuable material from oil palm empty fruit bunch by sub-critical water. J Oleo Sci 65 (4): 283-289. DOI: 10.5650/JOS.ESS15209.

Leifeld J, von Lützow M. 2014. Chemical and microbial activation energies of soil organic matter decomposition. Biol Fertil Soils 50: 147-153. DOI: 10.1007/s00374-013-0822-6.

Li Y, Li W. 2015. Nitrogen transformations and losses during composting of sewage sludge with acidified sawdust in a laboratory reactor. Waste Manag Res 33 (2): 139-45. DOI: 10.1177/0734242X14564642.

Manavalan T, Manavalan A, Heese K. 2015. Characterization of lignocellulolytic enzymes from white-rot fungi. Curr Microbiol 70: 485-498.

Madusari S, Lestari I, Irma SV 2018. Physico-chemical properties in degradation of oil palm solid waste by microbial inoculant and palm oil mill effluent. IOP Conf Ser Earth Environ Sci 187: 012023. DOI: 10.1088/1755-1315/187/1/012023

Mohammad N, Alam MZ, Kabbashi NA, Ahsan, A. 2012. Effective composting of oil palm industrial waste by filamentous fungi: A review. Resour Conserv Recycl 58: 69-78.

Pan I, Dam B, Sen SK. 2012.Composting of common organic wastes using microbial inoculants. 3Biotech 2 (2): 127-134. DOI: 10.1007/s13205-011-0033-5.

Sandra FY, Joann KW, Myrna JS, Janzen, H.H. 2011. Plant lignin and nitrogen contents control carbon dioxide production and nitrogen mineralization in soils incubated with $\mathrm{Bt}$ and non-Bt corn residues. Soil Biol Biochem 43: 63-69. DOI: 10.1016/j.soilbio.2010.09.012.

Shahbaz M, Yakov K, Sanaullah M, Heitkamp F, Zelenev V, Kumar A, Blagodatskaya E. 2017. Microbial decomposition of soil organic matter is mediated by quality and quantity of crop residues: mechanisms and thresholds. Biol Fertil Soils 53: 287-301. DOI: 10.1007/s00374-016-1174-9.

Shahriarinour M, Ramanan RN, Abdul Wahab MN, Mohamad R, Mustafa S, Ariff AB. 2011. Improved cellulase production by Aspergillus terreus using oil palm empty fruit bunch fiber as the substrate in a stirred tank bioreactor through optimization of the fermentation conditions. Bioresources 6 (3): 2663-2675.

Shilev S, Naydenov M., Vancheva V, Aladjadjiyan A. 2007. Utilization of by-products and treatment of Waste in the Food Industry. Springer, New York.

Sigoillot JC, Berrin JG, Bey M, Lesage ML, Levasseur A, Lomascolo A, Record E, Uzan BE. 2012. Fungal Strategies for Lignin Degradation. Adv Bot Res 61: 263-308. DOI: 10.1016/B978-0-12-4160231.00008-2.

Stewart CE, Moturi P, Follett RF, Ardell D. 2015. Lignin biochemistry and soil $\mathrm{N}$ determine crop residue decomposition and soil priming. Biogeochemistry 124: 335-351. DOI: 10.1007/s10533-0150101-8

Solikhin A, Hadi Y, Massijaya M, Nikmatin S. 2016. Basic properties of oven-heat treated oil palm empty fruit bunch stalk fibers. Bioresources 11 (1): 224-2237. DOI: 11.10.15376/Biores.11.1.22242237

Sorgatto M, Guimarães NCA, Zanoelo FF, Marques MR, PeixotoNogueira SC, Giannesi GG. 2012. Purification and characterization of an extracellular xylanase produced by the endophytic fungus, Aspergillus terreus grown in submerged fermentation. Afr J Biotechnol 11: 8076-8084. DOI: 10.5897/AJB11.2686

Udoetok I..2012. Characterization of ash made from oil palm empty fruit bunches (OEFB). Intl J Environ Sci 3: 518-524.

Yeoh YC, Chin NY, Tan CS. Ooi HS, 2012. Industrial-scale cocomposting of palm oil mill waste with starter cultures. J Food Agric Environ 10 (2): 771-775.

Young CC, Rekha PD, Arun AB. 2005. Trichoderma xylanase, their properties and application. Biotechnol 12 (56): 413-435.

Zibilske LM, Bradford JM. 2007. Oxygen effects on carbon, polyphenols, and nitrogen mineralization potential in soil. Soil Sci Soc Am J 71: 133-139. 